\title{
Correlation of changes in serum S100 $\beta$, NSE and inflammatory factor levels with MMSE and MoCA in intracranial tumor patients with cognitive impairment
}

\author{
DANFENG YU ${ }^{1}$, BOYI LIU ${ }^{1}$, GUOQUAN JIANG ${ }^{2}$, SHIWEN PEI $^{3}$ and HUAN PAN ${ }^{1}$ \\ ${ }^{1}$ Department of Critical Medicine, Shiyan Taihe Hospital, Shiyan, Hubei 442000; \\ ${ }^{2}$ Department of Neurosurgery, Wuhan Hanyang Hospital, Wuhan, Hubei 430050; \\ ${ }^{3}$ Department of Neurosurgery, The Third People's Hospital of Bengbu, Bengbu, Anhui 233000, P.R. China
}

Received November 25, 2019; Accepted December 17, 2019

DOI: $10.3892 / 01.2020 .11751$

\begin{abstract}
Changes in serum neuron-specific enolase (NSE) level, S100 $\beta$ protein concentration and inflammatory factor levels and their correlations with cognitive impairment Mini-Mental State Examination (MMSE) and Montreal Cognitive Assessment (MoCA) scores in intracranial tumor patients with cognitive impairment were explored. Seventy patients diagnosed with intracranial tumor based on clinical symptoms and computed tomography (CT) images were selected and divided into non-cognitive impairment group (MoCA score $\geq 26$ points, $n=44$ ) and cognitive impairment group (MoCA score $<26$ points, $n=26$ ) in accordance with the comprehensive cognitive function evaluation scores. Next, the serum NSE level, S100 $\beta$ protein concentration and inflammatory factor levels were detected, and their relationships with MMSE and MoCA scores were analyzed via Pearson's correlation analysis. The MoCA and MMSE scores in non-cognitive impairment group were higher than those in cognitive impairment group $(\mathrm{P}<0.05)$. NSE and S100 $\beta$ levels were higher in non-cognitive impairment group compared with cognitive impairment group $(\mathrm{P}<0.05)$. In addition, the levels of interleukin-6 (IL-6), IL-8 and tumor necrosis factor- $\alpha$ (TNF- $\alpha$ ) were higher in cognitive impairment group than those in non-cognitive impairment group $(\mathrm{P}<0.05)$. The levels of patient's serum NSE, S100 $\beta$ protein and inflammatory factors were negatively related to MMSE and MoCA scores $(\mathrm{P}<0.05)$. The changes in serum NSE, S100 $\beta$ protein and inflammatory factor levels in patients with cognitive impairment can reflect the severity of the disease to a certain extent and are directly related to cognitive impairment. Accurate and comprehensive
\end{abstract}

Correspondence to: Dr Danfeng Yu, Department of Critical Medicine, Shiyan Taihe Hospital, 32 Renmin South Road, Shiyan, Hubei 442000 P.R. China

E-mail: cai0392@126.com

Key words: intracranial tumor, cognitive impairment, S100 $\beta$, NSE, inflammatory factor, MMSE, MoCA assessment of cognitive function of patients and early development of effective and targeted cognitive interventions are of certain clinical practical value for the improvement of prognosis.

\section{Introduction}

In recent years, intracranial tumors have an increasing incidence rate (1) and high disability rate worldwide, becoming an important challenge threatening the life and health of humans. Moreover, the mortality rate is $2.16 \%$ among all malignant tumors, and it is the 9th leading cause of death from malignant tumors (2). With the improvements in neurosurgery techniques and adjuvant therapy technologies such as radiotherapy and chemotherapy, the survival rate has gradually increased, and the survival time is 5-15 years (3). Most patients with brain tumors often have manifestations such as cognitive impairment memory loss and language dysfunction (4). In clinical practice, the cognitive function of patients is comprehensively assessed via the Mini-Mental State Examination (MMSE) and Montreal Cognitive Assessment (MoCA). The mechanism of cognitive impairment in intracranial tumors is complex, and no definitive conclusion is made clinically. Theoretically, cognitive function is correlated with the brain tumors, related neurological complications and cerebral cortical structural basis. Some scholars analyzed the brain structure network to investigate the relationship between cognitive function and the tumors (5). Moreover, it is reported that cognitive impairment is closely related to tumor-related inflammatory responses (6). Inflammatory factors including tumor necrosis factor- $\alpha$ (TNF- $\alpha$ ) and interleukin-6 (IL-6) directly damage neuronal cells, resulting in cognitive impairment. In case of ischemia and hypoxia of the central nervous system due to various factors, serum neuron-specific enolase (NSE) and S100 $\beta$ protein are highly expressed in neuronal cells and glial cells, respectively. These two indexes can specifically reflect the damage to nerve cells and are considered to be the most sensitive indicators for brain tissue damage $(7,8)$. This study detected the changes in serum NSE level, S100 $\beta$ protein concentration and inflammatory factor levels and their relationships with cognitive impairment in MMSE and MoCA 
scores of intracranial tumor patients with cognitive impairment to provide certain practical basis for the early diagnosis and treatment of cognitive impairment in intracranial tumors.

\section{Patients and methods}

Clinical data. A total of 70 patients diagnosed with intracranial tumors based on clinical symptoms and computed tomography (CT) images and who underwent surgical resection in Shiyan Taihe Hospital from January 2018 to December 2018 were selected and divided into non-cognitive impairment group (MoCA scores $\geq 26$ points, $n=44$ ) and cognitive impairment group (MoCA scores $<26$ points, $n=26$ ) according to the comprehensive evaluation scores for cognitive function. Exclusion criteria: Patients treated with chemoradiotherapy or biologics 1 month prior to the evaluation, those unable to tolerate surgery due to serious disease of other organs, or those complicated by other cognitive impairments. The age, gender and education level of patients were comparable between the two groups $(\mathrm{P}>0.05)$.

The study was approved by the Ethics Committee of Shiyan Taihe Hospital (Shiyan, China) and signed informed consents were obtained by the patients and/or guardians.

Study methods. After admission, serum samples were collected to determine the NSE level, S100 $\beta$ protein concentration and inflammatory factor levels. On the same day, the comprehensive cognitive function evaluation was conducted by professionals using MMSE and MoCA scores, the age and education year of patients were recorded, and the neuropsychology of the patients was evaluated. The evaluation time was 5-10 min. The MMSE consists of 7 items: Time orientation, location orientation, delayed memory, immediate memory, attention and calculation capacity, linguistic competence and visuo-spatial structure, with a total score of 0-30 points. The MoCA includes visuo-spatial execution capability, attention, language fluency, naming ability, abstract thinking, orientation and delayed recall. Since the MoCA is affected by different education levels, cultural correction is necessary, and 1 point is added to the total score if the period of education is $\leq 12$ years. The comprehensive cognitive function evaluation score $<26$ points suggested cognitive impairment $(9,10)$.

Detection indicators. Fasting venous blood (3-5 ml) was collected from all the patients the next day after admission and centrifuged at $3,000 \times \mathrm{g}$ and $4^{\circ} \mathrm{C}$ for $10 \mathrm{~min}$, and then the supernatant was collected and stored at $-80^{\circ} \mathrm{C}$ for later detection.

The expression levels of serum NSE and S100 $\beta$ protein were measured using a CobasE411 automatic electrochemiluminescence analyzer.

A Sunrise automatic microplate reader (Decon) was used to detect the levels of serum IL-6, IL-8 and TNF- $\alpha$.

The cognitive function of patients was scored according to the items in the scales.

Statistical analysis. SPSS 20.0 software was used to analyze the data. Measurement data were expressed as mean \pm standard deviation (mean \pm SD), and LSD test was employed for comparison between two groups. Pearson's correlation
Table I. Comparison of serum NSE and S100 $\beta$ between the two groups (ng/l).

\begin{tabular}{lccc}
\hline Group & $\mathrm{n}$ & $\mathrm{NSE}$ & $\mathrm{S} 100 \beta$ \\
\hline $\begin{array}{l}\text { Non-cognitive } \\
\text { impairment group }\end{array}$ & 44 & $22.69 \pm 9.49$ & $1.22 \pm 0.46$ \\
$\begin{array}{l}\text { Cognitive impairment } \\
\text { group }\end{array}$ & 26 & $36.81 \pm 10.75$ & $1.85 \pm 0.51$ \\
t value & & & \\
P-value & & 6.876 & 5.257 \\
\hline
\end{tabular}

NSE, neuron-specific enolase.

analysis was employed to analyze the correlation of serum S100 $\beta$, NSE and inflammatory factor level changes with MMSE and MoCA. $\mathrm{P}<0.05$ was considered to indicate a statistically significant.

\section{Results}

Comparison of serum NSE and S100 $\beta$ expression levels between the two groups. The experimental results showed that the NSE and S100 $\beta$ levels were 22.69 \pm 9.49 and $1.22 \pm 0.46 \mathrm{ng} \cdot \mathrm{l}^{-1}$ in non-cognitive impairment group and $36.81 \pm 10.75$ and $1.85 \pm 0.51 \mathrm{ng}^{-1} \mathrm{l}^{-1}$ in cognitive impairment group, respectively. The expression levels of NSE and S100 $\beta$ protein were notably higher in cognitive impairment group than those in non-cognitive impairment group $(\mathrm{P}<0.05)$, implying that monitoring the changes in the expression of the two indicators is conducive to early intervention treatment (Table I).

Comparison of inflammatory factor levels between the two groups. The levels of IL-6, IL- 8 and TNF- $\alpha$ were 13.36 \pm 3.44 ,

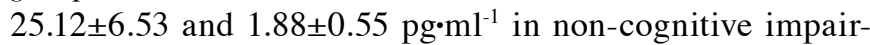
ment group and $28.58 \pm 5.02,38.77 \pm 7.95$ and $5.59 \pm 1.16 \mathrm{pg} \cdot \mathrm{ml}^{-1}$ in cognitive impairment group, suggesting that inflammatory factors are involved in the development of cognitive impairment (Table II).

Comparison of MoCA and MMSE scores between the two groups. The comparison of MoCA and MMSE scores (Table III) revealed that both MoCA and MMSE scores in non-cognitive impairment group were higher than those in cognitive impairment group $(26.71 \pm 0.82$ vs. $18.22 \pm 1.70$ points and $25.47 \pm 1.32$ vs. $20.18 \pm 1.86$ points, $\mathrm{P}<0.05)$, indicating that both MoCA and MMSE can directly reflect the severity of cognitive impairment in patients with intracranial tumors.

Correlation of various indicators with cognitive impairment scores. The correlation analysis of cognitive impairment scores with indicators such as inflammatory mediators, NSE and S100 $\beta$ protein showed that the levels of serum inflammatory factors (IL-6, IL-8 and TNF- $\alpha$ ), NSE and S100 $\beta$ were negatively correlated with MoCA score in patients with cognitive impairment ( $r=-0.4401,-0.5292,-0.6070,-0.272$ and -0.5089 , $\mathrm{P}<0.001$ ), proving that the increased expression of NSE and S100 $\beta$ protein in vivo indicate cognitive impairment, and the 
Table II. Comparison of inflammatory factor levels between the two groups (pg/ml).

\begin{tabular}{lcccc}
\hline Group & $\mathrm{n}$ & $\mathrm{IL}-6$ & $\mathrm{IL}-8$ & $\mathrm{TNF}-\alpha$ \\
\hline Non-cognitive impairment group & 44 & $13.36 \pm 3.44$ & $25.12 \pm 6.53$ & $1.88 \pm 0.55$ \\
Cognitive impairment group & 22 & $28.58 \pm 5.02$ & $38.77 \pm 7.95$ & $5.59 \pm 1.16$ \\
t value & & 3.145 & 3.876 & 2.778 \\
P-value & & $<0.05$ & $<0.05$ & $<0.05$ \\
\hline
\end{tabular}

IL, interleukin; TNF- $\alpha$, tumor necrosis factor- $\alpha$.

Table III. Comparison of MoCA and MMSE scores between the two groups.

\begin{tabular}{lccc}
\hline Group & $\mathrm{n}$ & MoCA & MMSE \\
\hline $\begin{array}{l}\text { Non-cognitive } \\
\text { impairment group }\end{array}$ & 44 & $26.71 \pm 0.82$ & $25.47 \pm 1.32$ \\
$\begin{array}{l}\text { Cognitive impairment } \\
\text { group }\end{array}$ & 26 & $18.22 \pm 1.70$ & $20.18 \pm 1.86$ \\
t value & & 6.133 & 3.256 \\
P-value & & $<0.01$ & $<0.05$ \\
\hline
\end{tabular}

MoCA, Montreal Cognitive Assessment; MMSE, Mini-Mental State Examination.

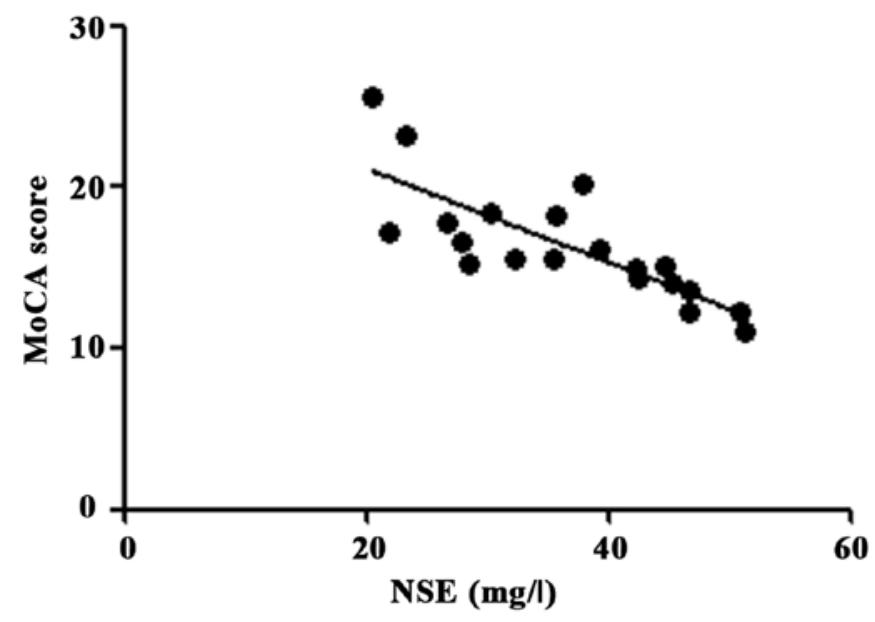

Figure 1. Correlation analysis of NSE and MoCA score $(r=-0.6272)$. NSE, neuron-specific enolase; MoCA, Montreal Cognitive Assessment.

abnormal expression of immune inflammatory factors in vivo is directly related to the development of cognitive impairment in patients (Figs. 1-5).

\section{Discussion}

It has been verified (11) that patients with intracranial tumors are complicated by varying degrees of cognitive impairment, with an incidence rate of $19-83 \%$ (12). Cognitive function, one of the important prognostic indicators for patients with brain tumors (13), is comprehensively evaluated using

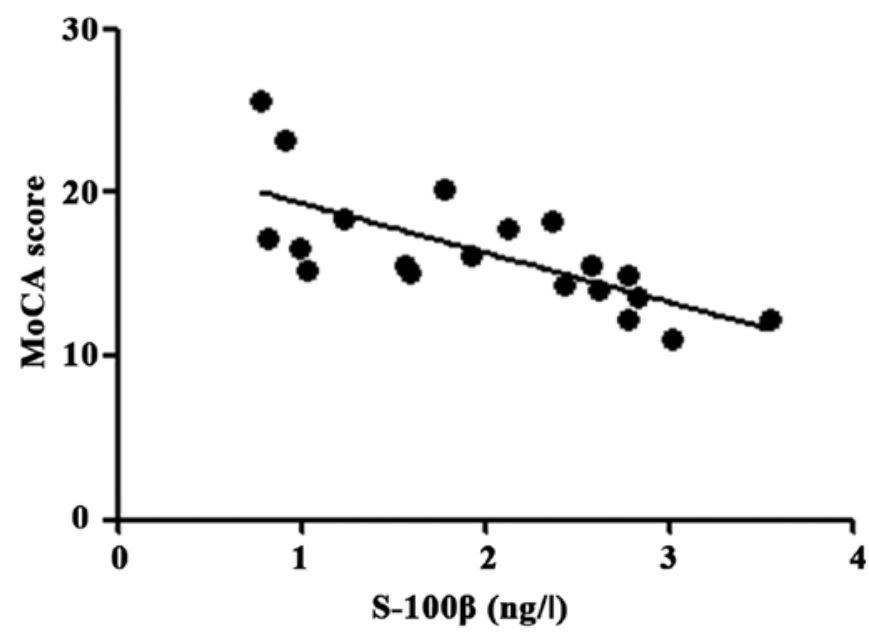

Figure 2. Correlation analysis of $\mathrm{S} 100 \beta$ and MoCA score $(\mathrm{r}=-0.5089)$ MoCA, Montreal Cognitive Assessment.

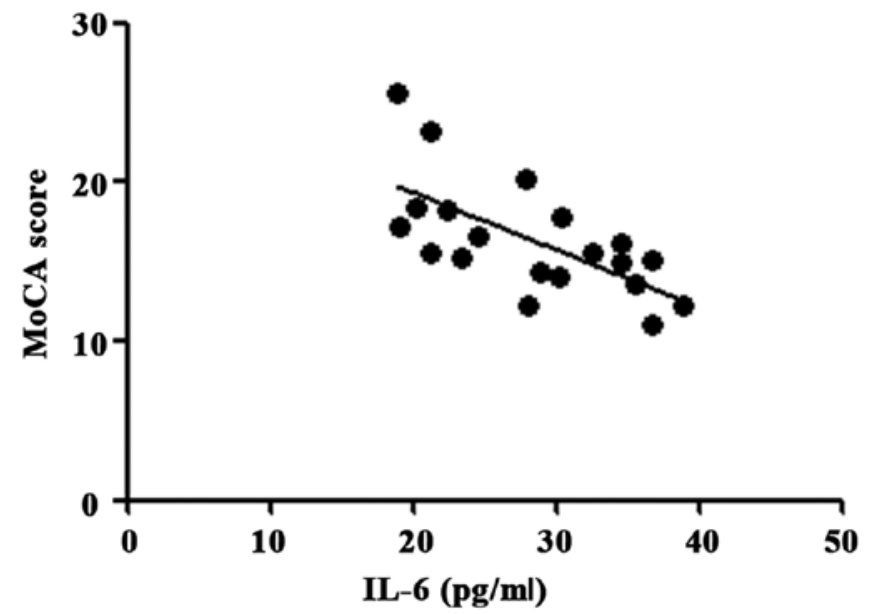

Figure 3. Correlation analysis of IL-6 and MoCA score ( $\mathrm{r}=-0.4401)$. IL-6, interleukin-6; MoCA, Montreal Cognitive Assessment.

MMSE and MoCA scores, respectively. MoCA has a relatively high diagnostic sensitivity and specificity (14). In this study, the MoCA and MMSE scores were compared between the two groups, and it was found that compared with those (18.22 \pm 1.70 and $20.18 \pm 1.86$ points) in cognitive impairment group, the scores of MoCA and MMSE (26.71 \pm 0.82 and $25.47 \pm 1.32$ points) were increased in non-cognitive disorder group $(\mathrm{P}<0.05)$, implying that both MMSE and MoCA are 


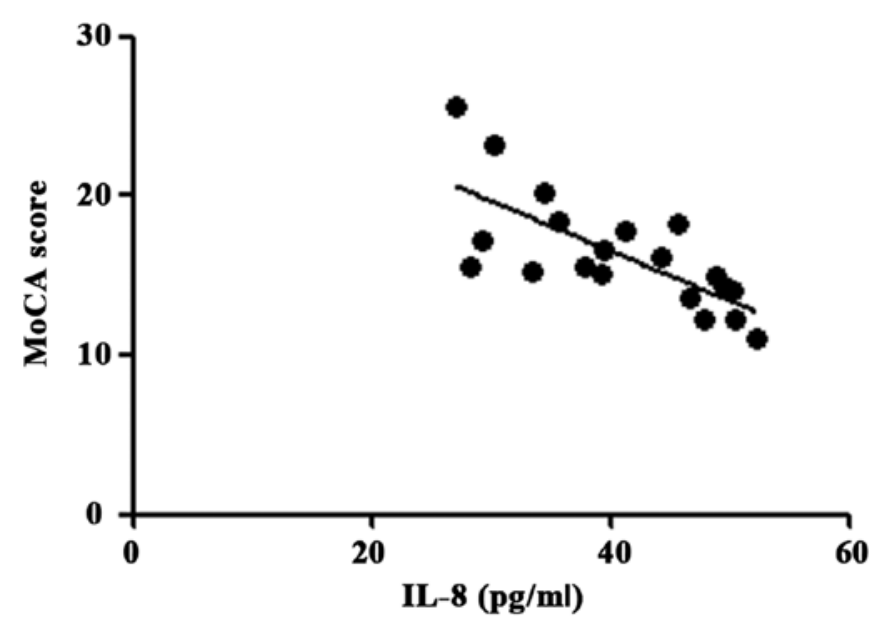

Figure 4. Correlation analysis of IL-8 and MoCA score ( $r=-0.5291)$. IL-8, interleukin-8; MoCA, Montreal Cognitive Assessment.

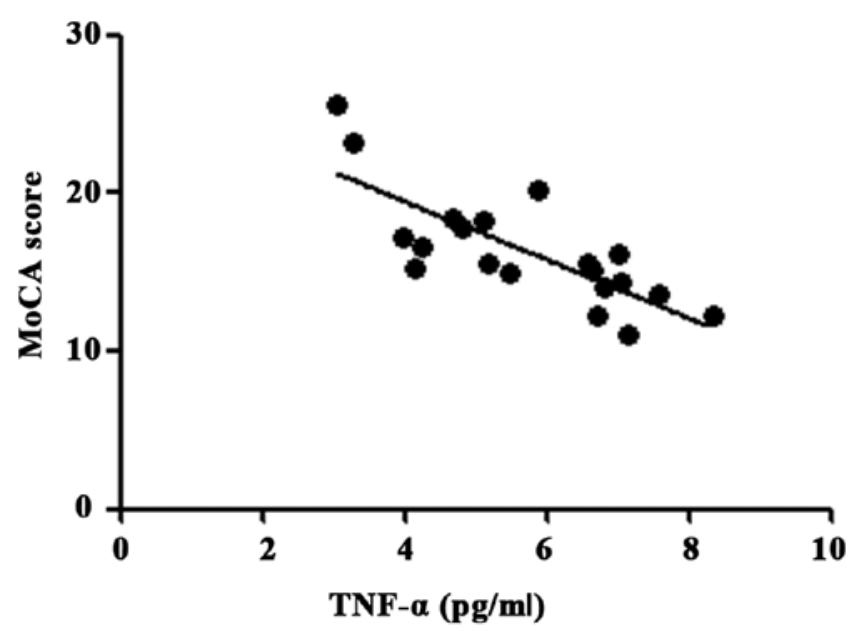

Figure 5. Correlation analysis of TNF- $\alpha$ and MoCA score ( $r=-0.6070)$. TNF- $\alpha$, tumor necrosis factor- $\alpha$; MoCA, Montreal Cognitive Assessment.

able to directly reflect the severity of cognitive impairment in patients with intracranial tumors. During the progression of the disease, patients with intracranial tumors generally have cognitive impairment (15) that may even occur earlier than the anatomical changes indicated by $\mathrm{CT}$ and MRI. Therefore, cognitive function examination is beneficial for clinicians to know the progression and possible recurrence of tumors in time.

When brain neuronal cells are damaged, increased concentration of NSE and S100 $\beta$ is detected in the peripheral blood. NSE is a specific enzyme for cerebral ischemia-hypoxia injury, and $S 100 \beta$ protein is associated with the degree of damage to the nervous system (7). A previous study (16) on patients with Alzheimer's disease discovered that serum S100 $\beta$ protein and NSE levels are related to cognition degree, i.e., the higher their expression levels are, the worse the cognitive function will be. It was found in this study that the NSE and S100 $\beta$ levels (22.69 \pm 9.49 and $\left.1.22 \pm 0.46 \mathrm{ng}^{-1}{ }^{-1}\right)$ in non-cognitive impairment group were lower than those $\left(36.81 \pm 10.75\right.$ and $\left.1.85 \pm 0.51 \mathrm{ng}^{-1} \mathrm{l}^{-1}\right)$ in cognitive impairment group $(\mathrm{P}<0.05)$, indicating that monitoring the changes in the expression of both indexes contributes to early intervention treatment. Researchers pay increasing attention to the role of inflammatory mediators in the development of cognitive impairment as clinical and basic studies have manifested (17). TNF- $\alpha$ is implicated in the physiological processes of learning and memory, and the cognitive function of mice with TNF- $\alpha$ gene knockout is evidently weakened. TNF- $\alpha$, as a promoter of the inflammatory cascade, can induce the production of cytokines including IL-6 and IL-8 (18), damaging neuronal cells and leading to the development and progression of cognitive impairment. It was revealed in statistical regression analysis in the study of inflammatory factors and cognitive impairment that elevated plasma IL-6 level is one of the risk factors for cognitive impairment (19). In this study, the relevant results showed that

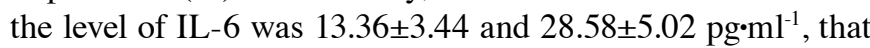

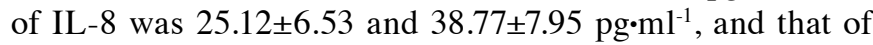
TNF- $\alpha$ was $1.88 \pm 0.55$ and $5.59 \pm 1.16$ pg. $\mathrm{ml}^{-1}$ in non-cognitive impairment group and cognitive impairment group, respectively. The expression levels of the above inflammatory factors were higher in cognitive impairment group than those in non-cognitive impairment group $(\mathrm{P}<0.05)$, implying that inflammatory factors participate in the development of cognitive impairment. As to the treatment of cognitive impairment, anti-infective therapy may help suppress its progression.

The correlation analysis of cognitive impairment scores with indicators such as inflammatory mediators, NSE and S100 $\beta$ protein displayed that the levels of serum inflammatory factors including IL-6, IL- 8 and TNF- $\alpha$, NSE and S100 $\beta$ protein were negatively related to MoCA score in intracranial tumor patients with cognitive impairment $(\mathrm{r}=-0.4401,-0.5292$, $-0.6070,-0.272$ and $-0.5089, \mathrm{P}<0.001)$, confirming that the increase in the expression of NSE and S100 $\beta$ protein in vivo suggests cognitive impairment, and the abnormal expression of immune inflammatory factors in vivo is directly associated with the development of cognitive impairment in patients.

In conclusion, the changes in serum NSE, S100 $\beta$ protein and inflammatory factors in patients with cognitive impairment reflect the severity of the disease to some extent, directly correlated with cognitive impairment. Accurately and comprehensively evaluating the cognitive function of patients and early developing effective and targeted cognitive interventions have certain clinical practical value for improving prognosis.

\section{Acknowledgements}

Not applicable

\section{Funding}

No funding was received.

\section{Availability of data and materials}

The datasets used and/or analyzed during the current study are available from the corresponding author on reasonable request.

\section{Authors' contributions}

DY wrote the manuscript. DY and BL collected and analyzed the general data of patients. GJ assisted with the detection 
of indicators. SP and HP were responsible for the statistical analysis. All authors read and approved the final manuscript.

\section{Ethics approval and consent to participate}

The study was approved by the Ethics Committee of Shiyan Taihe Hospital (Shiyan, China) and signed informed consents were obtained by the patients and/or guardians.

\section{Patient consent for publication}

Not applicable.

\section{Competing interests}

The authors declare that they have no competing interests.

\section{References}

1. Leece R, Xu J, Ostrom QT, Chen Y, Kruchko C and Barnholtz-Sloan JS: Global incidence of malignant brain and other central nervous system tumors by histology, 2003-2007. Neuro Oncol 19: 1553-1564, 2017.

2. Chen W, Zheng R, Baade PD, Zhang S, Zeng H, Bray F, Jemal A, Yu XQ and He J: Cancer statistics in China, 2015. CA Cancer J Clin 66: 115-132, 2016.

3. van Loon EM, Heijenbrok-Kal MH, van Loon WS, van den Bent MJ, Vincent AJ, de Koning I and Ribbers GM: Assessment methods and prevalence of cognitive dysfunction in patients with low-grade glioma: A systematic review. J Rehabil Med 47: 481-488, 2015

4. Gauthier S, Reisberg B, Zaudig M, Petersen RC, Ritchie K, Broich K, Belleville S, Brodaty H, Bennett D, Chertkow H, et al International psychogeriatric association expert conference on mild cognitive impairment: Mild cognitive impairment. Lancet 367: 1262-1270, 2006.

5. Derks J, Reijneveld JC and Douw L: Neural network alterations underlie cognitive deficits in brain tumor patients. Curr Opin Oncol 26: 627-633, 2014

6. Wärnberg J, Gomez-Martinez S, Romeo J, Díaz LE and Marcos A: Nutrition, inflammation, and cognitive function. Ann NY Acad Sci 1153: 164-175, 2009.

7. Markowitz J, MacKerell AD Jr and Weber DJ: A search for inhibitors of S100B, a member of the S100 family of calcium-binding proteins. Mini Rev Med Chem 7: 609-616, 2007.
8. Nguyen DN, Spapen H, Su F, Schiettecatte J, Shi L, Hachimi-Idrissi S and Huyghens L: Elevated serum levels of S-100beta protein and neuron-specific enolase are associated with brain injury in patients with severe sepsis and septic shock. Crit Care Med 34: 1967-1974, 2006.

9. Nasreddine ZS, Phillips NA, Bédirian V, Charbonneau S, Whitehead V, Collin I, Cummings JL and Chertkow H: The Montreal Cognitive Assessment, MoCA: A brief screening tool for mild cognitive impairment. J Am Geriatr Soc 53: 695-699, 2005.

10. Meskal I, Gehring K, van der Linden SD, Rutten GJ and Sitskoorn MM: Cognitive improvement in meningioma patients after surgery: clinical relevance of computerized testing. J Neurooncol 121: 617-625, 2015.

11. Olson RA, Chhanabhai T and McKenzie M: Feasibility study of the Montreal Cognitive Assessment (MoCA) in patients with brain metastases. Support Care Cancer 16: 1273-1278, 2008.

12. Boone M, Roussel M, Chauffert B, Le Gars D and Godefroy O: Prevalence and profile of cognitive impairment in adult glioma: A sensitivity analysis. J Neurooncol 129: 123-130, 2016.

13. Taphoorn MJ and Klein M: Cognitive deficits in adult patients with brain tumours. Lancet Neurol 3: 159-168, 2004.

14. Petersen RC, Doody R, Kurz A, Mohs RC, Morris JC, Rabins PV, Ritchie K, Rossor M, Thal L and Winblad B: Current concepts in mild cognitive impairment. Arch Neurol 58: 1985-1992, 2001.

15. Nasreddine ZS, Phillips NA, Bédirian V, Charbonneau S, Whitehead V, Collin I, Cummings JL and Chertkow H: The Montreal Cognitive Assessment, MoCA: A brief screening tool for mild cognitive impairment. J Am Geriatr Soc 53: 695-699, 2005.

16. Chaves ML, Camozzato AL, Ferreira ED, Piazenski I, Kochhann R, Dall'Igna O, Mazzini GS, Souza DO and Portela LV: Serum levels of S100B and NSE proteins in Alzheimer's disease patients. J Neuroinflammation 7: 6, 2010.

17. Baune BT, Wiede F, Braun A, Golledge J, Arolt V and Koerner H: Cognitive dysfunction in mice deficient for TNF- $\alpha$ and its receptors. Am J Med Genet B Neuropsychiatr Genet 147B: 1056-1064, 2008.

18. Barone FC, Arvin B, White RF, Miller A, Webb CL, Willette RN, Lysko PG and Feuerstein GZ: Tumor necrosis factor-alpha. A mediator of focal ischemic brain injury. Stroke 28: 1233-1244, 1997.

19. Weaver JD, Huang MH, Albert M, Harris T, Rowe JW and Seeman TE: Interleukin-6 and risk of cognitive decline: MacArthur studies of successful aging. Neurology 59: 371-378, 2002.

This work is licensed under a Creative Commons Attribution-NonCommercial-NoDerivatives 4.0 International (CC BY-NC-ND 4.0) License. 